\title{
THE GASKELL PRIZE AND MEDAL
}

(Value not less than $£ 30$ ).

\section{INew Regulations.}

Thrs Prize was founded in 1887 , to honour the memory of the late Mr. Samuel Gaskell, F.R.C.S., at one time Medical Superintendent of the Lancaster County Lunatic Asylum, Lancaster, and subsequently for seventeen years a Commissioner in Lunacy. Upon his death in 1886 , his sister, the late Mrs. Holland, gave $£ 1,000$ to this Association, and other members of the family subsequently contributed further sums amounting to $£ 340$. The interest of this sum is given annually as a prize to the candidate who shall most distinguish himself in an examination in the subjects hereunder mentioned.

The Examination must be held in England according to the terms of the Trust.

(I) Candidates must produce evidence-

(a) Of having attained the age of 23 .

(b) Of having been qualified Medical Officers in one or more Mental Hospitals or Clinics in Psychiatry in the United Kingdom or elsewhere in the British Empire for at least two years.

(c) Of possessing the Certificate in Psychological Medicine of this Association or a Degree or Diploma in Psychological Medicine of Universities and Examining Boards having the power to grant medical qualifications registrable in the British Isles or elsewhere in the British Empire.

(2) Candidates will be examined in-

(a) Psychology.

(b) Anatomy, histology and physiology of the nervous system, reproductive and endocrine glands, pathology of the above, especially in relation to mental disorders.

(c) The diagnosis, prognosis, treatment and legal relations of mental disorders.

(d) Clinical cases.

(3) A thesis based on original research, if of sufficient merit, may be accepted by the examiners in place of either the written or the clinical examination or both.

Note.-Attention is called to the fact that these regulations enable original research to be recognized.

\section{NOTICES OF MEETINGS.}

Quarterly General Meetings.-February 19, 1925, at Edinburgh ; May 21, 1925. South-Western Division.-April 23, 1925, at Brislington House, Bristol.

Northern and Midland Division.-In April, 1925, at Narborough.

Scottish Division.-In May, 1925, at Inverness.

Irish Division.-April 2, 1925, at the Stewart Institution, Chapelizod. 